\title{
Figura de la hija madre en la familia venezolana. Relato de vida de Simonne Gennaro
}

\author{
Figure of the mother daughter in the Venezuelan family. Life story of Simonne \\ Gennaro
}

Figura da filha mãe na família venezuelana. História de vida de Simonne Gennaro

Elsa De La Torre

delatorreelsa@gmail.com

Universidad de Carabobo, Valencia, Venezuela
Simonne Gennaro

simonegennaro03@gmail.com

Universidad de Carabobo, Valencia, Venezuela
RESUMEN

Partiendo del relato de vida; “Mi padre me dijo que estaría a cargo de mis dos hermanas, no logre tener una explicación, solo sé que nos llevaron a la casa de mi Nonna (la madre de mi papá). No comprendía lo que sucedía, pero la agonía cada día se hacía grande porque yo quería estar con mi Mamá". Esta investigación tuvo como intencionalidad hacer un estudio comprensivo sobre la figura de la hija madre en el contexto de la familia venezolana. Metodológicamente fue cualitativa de investigación convivida con enfoque biográfico de relato-devida (Moreno, 2016). El relato-d-vida, produjo 3 bloques respectivamente. A la luz de ello se habla de dos grandes temáticas, la resolución del problema por medio de la familia matricentrada los dispositivos culturales. Aportes a la orientación es haber develado como los dispositivos culturales se hacen presente para preservar la familia matricentrada.

Palabras clave: Familia popular venezolana, hija, madre, relato-de-vida, orientación
ABSTRACT

Starting from the life story; "My father told me that he would be in charge of my two sisters, I could not have an explanation, I only know that they took us to the house of my Nonna (my father's mother). I didn't understand what was happening, but the agony became great every day because I wanted to be with my Mom". The purpose of this research was to carry out a comprehensive study on the figure of the mother daughter in the context of the Venezuelan family. Methodologically, it was a qualitative one of coexisting research with a lifestory biographical approach (Moreno, 2016). The story-d-life, produced 3 blocks respectively. In light of this, two major themes are discussed, the resolution of the problem through the matricentre family and cultural devices. Contributions to orientation is to have revealed how cultural devices are present to preserve the matricentral family

Key words:

Venezuelan popular family, daughter, mother, life-story, orientation
RESUMO

A partir da história de vida; "O meu pai disse-me que ficaria a cargo das minhas duas irmãs, não pude dar uma explicação, só sei que nos levaram para a casa da minha nonna (mãe do meu pai). Eu não entendia o que estava acontecendo, mas a cada dia a agonia aumentava porque eu queria estar com minha mãe". O objetivo desta pesquisa é realizar um estudo abrangente sobre a figura da mãe-filha no contexto da família venezuelana. Metodologicamente, foi qualitativa de pesquisa coexistente com abordagem biográfica de histórias de vida (Moreno, 2016). A história-d-vida, produziu 3 blocos respectivamente. Diante disso, dois grandes temas são discutidos, a resolução do problema por meio da família do matricentro e os dispositivos culturais. Contribuições para a orientação é ter revelado como os dispositivos culturais estão presentes para preservar a família matricentral.

Palavras-chave:

Família popular venezuelana, filha, mãe, história de vida, orientação 


\section{INTRODUCCIÓN}

Para Durkheim, (1973) la familia es el lugar de orden, normativo y básico, aunque heterogéneo, en el que actúan, al igual que en la sociedad, fuerzas de aprobación y sanción.

Sin embargo, hace ya varias décadas el valor de la familia está decayendo por este sentido, son pocos los casos que inician una familia bajo el matrimonio, o que se constituyan esencialmente como conocíamos una familia tradicional 0 triangular, en nuestra actualidad, pleno siglo XXI hay una gran gama de variedad de tipos de familias que entre ellos están; familia nuclear, padres e hijos, familia extensa, familia monoparental, entre otras.

Por lo tanto, Moreno (1997) señala que, el modelo de familia nuclear se volvió cada vez más inalcanzable, no tanto porque la gente creía menos en él, sino porque para una porción creciente de la población resultaba cada vez más difícil ajustarse a las formas de comportamiento esperadas. En Venezuela, la familia se caracteriza por el conjunto de relaciones que se entrelazan con sus miembros y que giran en torno a una mujer que es la madre; esto significa que la familia venezolana es matricentrada porque está representada por la presencia de una mujer-madre.

Los modelos de familias venezolanas son muy variados entre ello en Venezuela lo compone el matrimonio civil, y eclesiástico, concubinato, madre e hijos, padre e hijos en donde la presencia del padre en la familia es fundamental siendo él la cabeza del hogar, pero cuando el padre está ausente la madre toma el rol de padre y madre a la vez, siendo ella una figura primordial para sus hijos y es ahí donde se habla de una familia matricentrada.

Cabe destacar que, de ninguna manera Venezuela, es la única región donde predomina la familia matricentrada: Ha sido ampliamente documentada en países del Caribe, entre la población negra y blanca pobre de los EE. UU, en algunos sectores de España y Portugal (Shoumatoff, 1990).

El problema radica cuando ninguno de los padres no toma esta figura; partiendo de esto, se hace énfasis la investigación, ya que trata de una hija que desde muy tierna edad se hizo cargo de sus dos hermanas, porque sus padres no podían hacerse cargo de ellas, de esta forma, se puede encontrar la similitud de la familia popular venezolana que explica que la hermana está destinada a ser madre cuando los padres llegan a estar ausentes. Así que, el contexto venezolano presenta continuamente la familia matricentrada y pueden variar las historias, pero el resultado es siempre igual.

En este sentido, la presente investigación tiene como propósito, hacer un estudio comprensivo sobre la figura de la hija madre en el contexto de la familia venezolana desde el relato de vida de Simonne Gennaro.

Esta investigación sacó a relucir la importancia del papel que juega la hermana mayor en la vida de sus hermanas menores, siendo ella la figura que hace que sus hermanas se sientan motivadas y afectuosas, ya que la hermana mayor por su instinto materno, trata de brindar seguridad y estabilidad a sus hermanas como mujer y madre.

\section{Marco teórico}

\section{La familia popular venezolana}

La familia, es el núcleo de todo ser humano, donde se forman en valores para el futuro destacando que es la base fundamental de la sociedad, compuesta por personas unidas por parentesco o relaciones de afecto. Sin embargo, lo más común es que esté constituida por personas con parentesco. 
Por otro lado, Moreno (2016) señala que el modelo familiar popular venezolano está bajo la influencia de la familia matricentrada.

Cuando Moreno se refiere a un modelo de familia popular quiere dar a entender que la forma en la cual se ha estructurado la familia en Venezuela no es algo de momento, sino que al transcurrir del tiempo se ha dado y que, dado en el mismo, teniendo como característica primordial de integración familiar “Mujer- Madre e hijos.

A su vez la familia matricentrada, tanto para la mujer como para el hombre populares, la familia y, en ella, la madre-familia, es el significado cultural más profundo". (Moreno, 2016, p.343).

\section{Matricentrismo}

Moreno (2012) postula que en Venezuela es muy común ver a madres solteras, siendo las que sustentan el hogar y que cumplen con total capacidad la función de padre, así éste se encuentre presente. Sin duda la madre tiene el don de MujerMadre, ya que sin importar quién sea el padre, ella velara por conformar su hogar y por sus hijos. (p. 7)

Se explica entonces, que el matricentrismo: es la estructuración de la familia, donde la madre es la figura esencial que preside los procesos afectivos al ejercer el rol del centro de las relaciones de parentesco; es decir es el motor dándole funcionalidad a su entorno, asume el cargo de socializar a los niños e identificarse fuertemente con los hijos, especialmente con las hijas; debido a que la hija está destinada a ser formada como mujer-madre.

\section{MÉTODO}

La investigación estuvo enmarcada dentro de la metodología cualitativa convivida, con un método relato de vida y un enfoque biográfico, porque centra el esfuerzo en investigar la realidad del mundo de vida popular venezolano, desde dentro, desde los significados y el sentido que le es propio.

Adicional, el diseño que se utilizó para el desarrollo de la investigación estuvo basada en las fases del relato de vida, el cual estuvo conformada por: prehistoria del relato de vida, relato de vida, e interpretación.

La fiabilidad del relato de vida, que se usó en el estudio, fueron las planteadas por Cartanni (1982), el primer criterio usado para la validación fueron las referencias de la vida cotidiana, el segundo criterio fueron los encuentros constantes con el narrador y el tercer criterio, la observación.

\section{RESULTADOS}

\section{Relato de vida de Simonne Gennaro}

Simonne Gennaro de 23 años nació en Venezuela, estudio Orientación en la Universidad de Carabobo, fue una mujer que desde su infancia tuvo que hacerse responsable de sus hermanos menores, dado a la ausencia de sus padres, generando marcas en su vida. De esta forma, el relato de la historia de vida de ella, se bifurcará en tres bloques para su interpretación.

\section{Mi padre me dijo que estaría a cargo de mis hermanas}

Fue un día, pensé que sería como cualquier otro, pero no fue así... mi padre me dijo que estaría a cargo de mis dos hermanas, no logre tener una explicación, solo sé que nos llevaron a la casa de mi Nonna (la madre de mi papá). No comprendía lo que sucedía, pero la agonía cada día se hacía grande porque yo quería estar con mi mamá, y no solo nos mudaron de casa sino también de estado, antes vivíamos en San Fernando de Apure y ahora estaríamos en Calabozo estado Guárico. Era algo nuevo cuidar de mis hermanas, observar lo que hacían, tener que hacer los oficios 
de la casa como lavar la ropa, fregar, escucharlas, tener que responder sus incógnitas, exhortarlas constantemente y todo aquello que se presentara que fuesen necesarios resolver.

Gennaro, pone al tanto de que ese día no sería usual sino totalmente distinto a los demás, lo que traería para ella algo inesperado donde expresó "mi padre me dijo que estaría a cargo de mis dos hermanas". Por lo que, la responsabilidad no debía pasar a la menor, empezando, que son los padres y representantes quienes deben asumir el cargo, el derecho y el deber de responder a las necesidades de sus hijos. Como bien lo estipula la Ley orgánica para la protección del niño y del adolescente, en sus artículos 1,25 y 26.

A su vez, en medio de la autoridad del padre constó la ausencia de él en la familia, debido a que ya no estuvo en el ámbito físico como tampoco en el emocional, lo que le permitió a la hija reconstruirlo o en caso similar buscar a un padre putativo. Por lo tanto, fue una relación de padre a hija que consta de la familia popular venezolana con el enfoque matricentrada, ya que por sí mismo no cumple con su figura, pues el padre lo que hizo fue delegar un mandato, en este caso en la niña y la madre es decir la abuela.

Por otro lado, es necesario que Gennaro le dice "la Nonna" a la abuela, debido a que ella, se casó con un italiano, pero éste no era el papá biológico del padre de Gennaro, sin embargo, fue él quien influyo porque lo crio con una cultura europea.

Agregado a ello genéticamente, el padre de Gennaro es de descendencia árabe. Por otro lado, la madre paterna es venezolana nacida en el campo. En unión a su esposo italiano tuvo un hijo y una hija. Aun en medio de esta unión del europeo con una mujer latina, la abuela continuó con la cultura de una familia matricentrada y popular, ya que apoyó a su hijo y aceptó criar a las niñas.

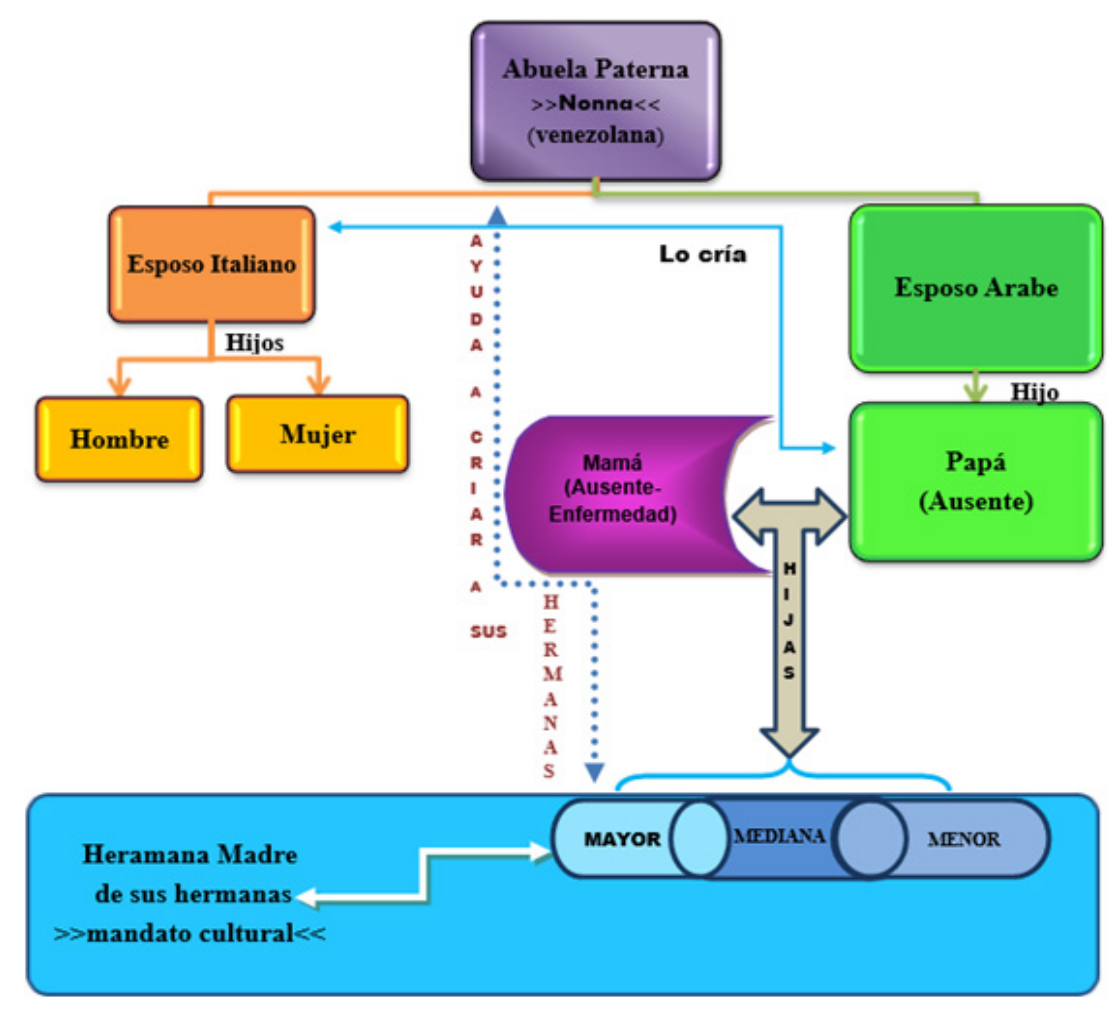

Figura 1. Estructura familiar de Gennaro Simonne. 
Además, consecuentemente Gennaro expresó "pero la agonía se hacía grande porque yo quería estar con mi mamá" siendo ella una niña comprendió que quería estar bajo el cuidado de su madre, una separación tendría consecuencias en su mundo de vida. Por ello, Moreno (2016) recalca, la relación es el significado fundamental del mundode-vida popular, una relación con énfasis en la figura materna. No cualquier relación, por tanto, sino una relación que se constituye y se forma en la madre y desde la madre.

A su vez, Gennaro acotó que se mudaron de casa y a su vez a otro estado de Venezuela en ese periodo de su vida, por lo que el proceso aun fue más complicado, ya que debió adaptarse al nuevo hogar. De esta forma reseñó; "y no solo nos mudaron de casa sino también de estado, antes vivíamos en San Fernando de Apure y ahora estaríamos en Calabozo estado Guárico."

Aunado a ello, con la corta edad que tenía Gennaro, asumió el significado de madre para sus hermanas, ya que no se trataba de tener alguna otra alternativa, la implicancia era evidente, siendo hija le fue dado el legado cultural de madre, mujer que reproduce y atiende a sus hijos, aun sin tener apoyo de la pareja u otro personaje, en este caso, la relación directamente con sus hermanas fue materna, lo que con mayor razón cumple el rol de cuidadora.

\section{Llamar a papá era algo inútil, decirle a mama no era de mucha ayuda}

...sino hacían caso también debía hacerme cargo, llamar a papa era algo inútil, decirle a mamá no era de mucha ayuda, en su defecto, no sabía qué hacer en cada situación, no fue fácil hacer lo correcto en toda ocasión. Aunque confieso que nunca estuve sola, mi apoyo incondicional fue Dios, algunas personas que se congregaban en la iglesia, los pastores, fueron ellos lo que ayudaron en áreas espiritual, emocional, física. Por otro lado, mi Nonna hacia lo que podía y mi tío paterno asumió el rol de papá sin darse cuenta, y así entre otras personas como vecinos o conocidos, recuerdo que nos ayudaron a nuestro crecimiento.

Se evidenció, la ausencia del padre, dado a que Gennaro en situaciones de conflictos con sus hermanas, buscaba de su ayuda creyendo que por la autoridad de padre que tenía, podría solventar dichos problemas. Y en caso de la madre, la ausencia no le permitió tampoco, satisfacer la ayuda necesaria que requería en el momento. Es decir, en sus padres, Gennaro no encontró las respuestas ni las soluciones, por lo que reiteró que hacerse cargo de sus hermanas era muy difícil.

Sin embargo, Gennaro, en medio de su búsqueda de figura madre significativa, encontró por medio de la fe, lo que le permitió formarse y encontrar apoyo en las áreas personales que requería.

A pesar que Gennaro contaba con la Nonna, por el hecho de recibirlas y criarlas, aun así, la Nonna no tomó toda la responsabilidad, dejándole a la niña mucho. La abuela en su conocimiento cultural llevo a su nieta a ser madre, no tomo a las tres para que fuesen niñas, de modo que le inculcó a la nieta mayor a que fueses más que un apoyo para sus hermanas.

La investigadora presume que Gennaro, no veía a la abuela como figura de madre significativa por lo que hace entender el motivo de la búsqueda de la figura madre.

Por lo tanto, Gennaro, trae a colación que su crecimiento fue parte de aquellos que estaban a su alrededor, aun sin ser familiares sanguíneos, se hicieron parte del mundo de ella, ya que los vecinos, conocidos pueden ayudar a la falla de madre. 


\section{Nueve años supe por medio de una conversación con mi papá que no podía estar con mi mamá por su trastorno bipolar}

...nueve años supe por medio de una conversación con mi papa que no podía estar con mamá por su trastorno bipolar, seguía sin entender, pero estaba esa voz en mi mente, estas a cargo de tus hermanas, quería despertar de esa pesadilla, era lo que pensaba, pero no fue así. Descubrí la esencia de mi vida, le encontré sentido, entonces si pude cambiar y ser mejor, acepté que lo que estaba pasando no era el fin del mundo, que no fui la única niña que estuvo a cargo de sus hermanas, e inicié nuevos métodos de cuidado. No siempre fueron buenos los resultados, pero puedo decir que todo ha valió la pena.

Gennaro conoció la causa de la falla de la madre por medio de una conversación con su padre, la trama se presentó desde otro punto de vista, ya que, no fue la misma platica que tuvo cuando tenía siete años, ahora con nueve años que tenía la relatora su padre conversó con ella y le explicó que su madre sufría de una enfermedad llamada trastorno bipolar, pero aun así se debe resaltar que una niña de nueve años de edad no puede comprender de que trataba dicho trastorno, sin embargo, lo que sí pudo comprender y asumir era que si no estaba su madre, la relatora si debía estar con el rol-figura de madre.

De esta manera, Gennaro, "quería despertar de esa pesadilla" pero prontamente aceptó que aquello que culturalmente le tocaba, no se trataba de un capricho del padre, el hecho de dejarlas solas, tampoco era un capricho de la Nonna ni aun de su madre, bajo la contingencia de su enfermedad, donde no logra y no puede controlar sus cambios de humor comprende y asume entonces la cultura, en la que nació, ahora el enfoque de la relatora concluye en enfocarse a buscar alternativas para seguir creciendo y continuar ayudando a su hermanas.

\section{CONCLUSIONES}

Por medio del relato de vida de la hija quien se hizo madre de sus hermanas por designios culturales y a su vez siendo estudiante de educación mención orientación del décimo semestre, reveló la vivencia y experiencia desde la persona, Demostró la esencia del significado que representa ser hija madre, siendo admirable que, a pesar de tener tierna edad, de no comprender lo que sucedía, asumió con vigor y responsabilidad dicho labor, enseñando la naturaleza madrada que forma parte de la cultura venezolana.

El significado de la hija madre, es sinónimo de valentía, constancia, sabiduría e inteligencia, descubrió al transcurrir del tiempo que su función fue y es necesario, de lo contrario el resultado de sus hermanas estuviese bajo contingencias irreversible, la hija madre deparo la circunstancia infalible en el contexto venezolano, dejando un ejemplo a seguir para aquellos por los que han pasado por la misma circunstancia o en caso contrario, comprender el mundo de vida de aquellos que la viven.

\section{REFERENCIAS}

Catani, M. y Mazé S. (1982). Tante Suzanne: une histoire de vie sociale. París : Librairie des Méridiens

Durkheim, E. (1975). Introducción a la sociología de la familia. En V. Karady (Comp.) Textes II, III. Paris, Francia: Minuit

Ley Orgánica para la Protección de Niños, Niñas y Adolescente (2007). Gaceta oficial (5859 extraordinaria) 10/12/2007. Asamblea nacional de la República Bolivariana de Venezuela

Moreno, J (1997). Sexo, matrimonio y familia: la ilegitimidad en la frontera pampeana del Río de la Plata, 1780-18 
Moreno, A. (2012). La familia popular venezolana. Temas de formación sociopolítica. Centro Gumilla. Publicaciones UCAB. Caracas, Venezuela

Moreno, A. (2016). Antropología Cultural Del Pueblo Venezolano. Caracas-Venezuela. Editorial Fundación Empresas Polar/CIP
Moreno A. (2016). La familia popular venezolana. Extraído de http://lafamiliapopularvenezolana. blogspot.com/ en abril de 2016

Shoumatoff, A. (1990). The Mountain of Names: A History of the Human Family. New York: Vintage Groups 